\title{
Rapid divergent evolution of an annual plant across a latitudinal gradient revealed by seed resurrection
}

\section{Running title: Rapid divergent evolution of plant traits}

Wendy A. Valencia-Montoya ${ }^{1 * \dagger}$, Elodie Flaven ${ }^{2}$, Juliette Pouzadoux ${ }^{2}$, Eric Imbert $^{2}$, Pierre-Olivier Cheptou $^{1 *}$

${ }^{1}$ CEFE UMR 5175, CNRS, Université de Montpellier, Université Paul-Valery Montpellier, EPHE, Montpellier Cedex 05, France ${ }^{2}$ ISEM, University of Montpellier - Montpellier, France

$\uparrow$ Present address: Department of Organismic and Evolutionary Biology and Museum of Comparative Zoology, Harvard University,

Cambridge, MA

"Corresponding authors: Wendy A. Valencia-Montoya: valenaturaa@gmail.com and Pierre OlivierCheptou: pierre-olivier.cheptou@cefe.cnrs.fr

Author contributions: P.O.C. and E.I. conceived the study, performed the common garden experiment, and measured growth-related and reproductive traits at the common garden experiment. W.A.V-M. measured performance traits such as seed set and seed predators. E.F. and J.P. genotyped individuals. W.A.V-M. conducted data analysis. W.A.V-M. wrote the paper with discussions and contributions from all authors. P.O.C. supervised the entire project. No conflict of interest to declare.

\section{Acknowledgments}

We thank all the people involved in the setting up of the field experiment and the data processing, in particular Lisa Petit, Justine Jones, and David Carbonell. We are also grateful to Yenny Correa for helping transcribing seed set data and Guillaume Papuga, Dinah Parker, Alejandra Duque, Federico Tamayo, Hilde Schneemann, and Neil Rosser. for providing critical comments on the manuscript. This project has been made possible thanks to the French Botanical Conservatories; thus, we are particularly indebted to Bertille Valentin from the CBN de Bailleul, Julien Geslin from the CBN de Brest, and Lara Dixon from the CBN Méditerranéen. The experiment was performed in the "Terrains d'Experiences" platform of the Labex Cemeb. Microsatellite genotyping was carried out at the Platform Genseq of the LabEx 'Centre Mediterranéen Environnement Biodiversité' (Montpellier, France). W.A.V-M. was also supported by the European Union through the Erasmus Mundus Master in Evolutionary Biology (MEME 2017-2019). This study was financially supported by the RapAdap Labex Cemeb project. This project did not receive money from MUSE (Montpellier Université d'Excellence). 
Data deposited on dryad : doi:10.5061/dryad.gtht76hn5

1 Rapid divergent evolution of an annual plant across a latitudinal gradient revealed by seed

\section{resurrection}

Abstract - Global change are expected to drive short-term evolution of natural populations. However, it remains unclear whether different populations are changing in unison. Here, we study contemporary evolution of growth-related and reproductive traits of three populations of Cyanus segetum across a latitudinal gradient in France. We resurrected stored seeds sampled up to 24 years apart from northern, central-western, and southern populations and conducted an in situ common-garden experiment. To disentangle neutral from selection-driven differentiation, we calculated $F_{S T}$ and $Q_{S T}$ between temporal samples. We found that phenotypic evolution was divergent across populations exhibiting different trends for rosette size, date of flowering, and capitula size. By measuring seed set as a proxy of fitness, we showed that samples with larger mean capitula size outperformed samples with smaller mean capitula size in the western and southern populations. Regression of traits on seed set showed that flowering date and capitula size are the primary determinants of fitness, and $Q_{S T} F_{S T}$ comparisons indicated that natural selection has likely contributed to the shifts in flowering phenology and rosette size. These findings outline the potential for rescue of natural populations through contemporary evolution and emphasize the complex interplay between spatial and temporal variation in species' responses to global change.

Keywords: climate change, adaptation, pollinator decline, resurrection study.

\section{Introduction}

Across the globe, ecosystems are experiencing simultaneous changes in climate, atmospheric composition, pollutant deposition, habitat loss, and fragmentation through land-use intensification ( $\mathrm{Yu}$ et al. 2016; Zhu et al. 2016). These anthropogenic disturbances have the potential to rapidly modify selection regimes in natural populations, triggering phenotypic change (Lopez-Gallego and O'Neil 2010; O'Brien et al. 2017). Although trait changes can occur due to phenotypic plasticity, growing evidence indicates that global change is a strong driver of genetic evolution in plant and animal communities at an ecological time-scale (Franks et al. 2007; Cheptou et al. 2008; Franks and Hoffmann 2012). Adaptation of natural populations to new conditions may buffer the impact of global change through short-term responses of growth-related traits and reproductive strategies (LopezGallego and O'Neil 2010; Brys and Jacquemyn 2012). Yet, to what extent adaptation can rescue populations will depend on the interaction between the local selection regimes, the rate of 
environmental deterioration, and the standing genetic variation (Franks and Hoffmann 2012; Thomann et al. 2015).

Contemporary plant evolution has been documented in response to different components of global change, including temperature increase, droughts, habitat degradation, spread of invasive species, chemical pollutants, and pollinator decline (Antonovics et al. 1971; Franks et al. 2007; Lopez-Gallego and O'Neil 2010; Sultan et al. 2013; Yu et al. 2016). Increased temperatures and severe droughts hinder plant growth and influence phenology by shifting flowering time (Franks et al. 2007; Yu et al. 2016; Zhu et al. 2016), while habitat loss and fragmentation result in the loss of genetic diversity and decreased gene flow (Lopez-Gallego and O'Neil 2010; Frei et al. 2014). Beyond detecting phenotypic change over time, a handful of studies have also addressed the role of natural selection in driving rapid evolution under global change through the calculation of selection differentials (Parachnowitsch and Kessler 2010), $Q_{S T}-F_{S T}$ comparisons (Rhoné et al. 2010; Thomann et al. 2015), and more recently, genome-wide scans (Franks et al. 2016; Frachon et al. 2017).

As part of global change, pollinator decline is a major ecological factor promoting evolution of plant reproductive traits (Thomann et al. 2013). Declines in pollinator visitation reduce plant fitness in allogamous species by inducing strong pollen limitation and hindering pollen transfer (Thomann et al. 2013; Thompson et al. 2013). Plants are predicted to respond to pollen limitation either by favouring the evolution of autonomous self-fertilization as a reproductive assurance strategy (Schemske and Lande 1985; Cheptou et al. 2008), or by evolving greater investment in pollinator attraction (Brys and Jacquemyn 2012; Thomann et al. 2015; Ramos and Schiestl 2019). Therefore, strict outcrossing species, such as self-incompatibles, are presumed to reinforce interactions with pollinators to increase visitation rates and efficiency of pollen transfer (Thomann et al. 2013). Traditionally, pollinatordriven selection has been studied for reproductive traits such as flowering phenology, number of open flowers, corolla size, anther-stigma distance or position, and floral morphology (Harder and Johnson 2009; Bodbyl Roels and Kelly 2011; Ramos and Schiestl 2019). Among these traits, traits related to corolla size and floral phenology have been shown to be under selection for strict outcrossing species. For instance, Thomann et al. (2015) used a common-garden experiment with stored seeds of the outcrossing Cyanus segetum and showed that in an interval of 18 years the studied population flowered earlier and produced larger capitula with longer receptivity and a larger floral display. However, this study was limited to one population whereas different locally adapted populations might show diverse mechanisms to ensure pollinators' visitation (Brys and Jacquemyn 2012). In the context of global pollinator decline, differences in selective pressures can result from heterogeneity of populations proximal to forested or disturbed areas affected by pesticides, which 
Hence, although global change components show similar trends across diverse terrestrial ecosystems, pollinator-driven selection can strongly vary at fine-geographic scales (Brys and Jacquemyn 2012). Recent studies have used a resurrection approach to show rapid evolution of populations triggered by climate change and historical droughts across latitudinal gradients (Dickman et al. 2019; Lambrecht et al. 2020; Vtipil and Sheth 2020; Wooliver et al. 2020). However, most of these studies of contemporary evolution in response to global change have focused on showing the direction and tempo of the evolutionary change using only phenotypic data, (Franks et al. 2007; Thomann et al. 2015), thus neglecting the role of genetic drift and gene flow in explaining populations' evolutionary responses.

In this study, we investigated short-term evolution of growth-related and reproductive traits in three populations of the cornflower Cyanus segetum Hill (syn. Centaurea cyanus L.). We addressed if the direction of the evolutionary change is consistent across different populations throughout a latitudinal gradient in France. We used a combined approach of growing resurrected propagules and commongarden experiments, which allows detection of evolution while excluding plasticity, thus revealing the direction and tempo of the evolutionary process (Franks et al. 2008a; Thomann et al. 2015). We germinated stored seeds sampled 16, 23 and 24 years apart for South, North and Central-West populations, respectively. We conducted common-garden experiments in field conditions and compared growth-related and reproductive traits, as well as seed set between sampled years, to test whether: 1) evolution of growth-related or reproductive traits occurred; 2) if the direction of phenotypic change is the same for the three populations; 3 ) if natural selection has contributed to trait changes by $Q_{S T} F_{S T}$ comparisons and selection gradients, 4) and whether the phenotypic changes between temporal samples translate into differences in population performance at the common garden experiment by taking seed set and number of capitula as a proxy of fitness.

\section{Material and methods}

Studied species, sampling area, and climatic data

The cornflower, Cyanus segetum (Asteraceae) is a self-incompatible annual plant that used to be common in cereal fields (Le Corre et al. 2014). Nonetheless, C. segetum, along with other rare weeds particularly in western Europe, have experienced severe declines since the second half of the twentieth century (Le Corre et al. 2014; Albrecht et al. 2016; Wilson 2017). C. segetum is insect-

105 pollinated and produces blue capitula with peripheral sterile florets and central mono-ovulate flowers

106 (Thomann et al. 2015).

107 Three populations were sampled to represent a latitudinal gradient from the northern, central-western 
108 and southern regions of France. The northern population is located near Breilly in Picardie (North of 109 France; 49 $55^{\prime} 21.24^{\prime \prime} \mathrm{N}, 2^{\circ} 09^{\prime} 25.40^{\prime \prime} \mathrm{E}$ ) (Figure 1A) and is surrounded by very few other cornflower 110 populations (Thomann et al. 2015). Seeds were collected in 1992, 2010 and 2015, thus 18 and 5 years 111 apart by the National Botanical Conservatory of Bailleul (CNBL) from the same agricultural field. 112 Seeds and seedlings from the Western population were collected in an agricultural field situated in Le 113 Mesnil-en-Vallée in Maine-et-Loire (Central West of France; 47¹8'27.7463' 'N, 1³'28.7636' 'W) 114 (Figure 1A) at an interval of 24 years (1991 and 2015, CBN of Brest). This area, known as the Loire 115 valley, has experienced a dramatic agricultural intensification in the last 50 years and is the leading 116 horticultural producer in France (Chambres d'agriculture des Pays de la Loire 2013). Seeds from the 117 southern population were collected 16 years apart (1999 and 2015) from the regional park "Parc 118 Naturel Régional de Luberon" close to the Commune Beaumont-de-Pertuis in the Vaucluse 119 department (Southeast of France; 4346'10.056'N, 541'28.68'”) (Figure 1A). The cornflower 120 seeds from this population were recollected in an agricultural field close to a vineyard (CBN 121 Méditerranéen). To explore how climatic variables have changed over time and across sampled 122 populations in France, we gathered data on monthly historical temperature (Tmin, Tmax; ${ }^{\circ} \mathrm{C}$ ) and 123 precipitation $(\mathrm{cm})$ from CRU-TS 4.03 (Harris et al. 2014) downscaled with WorldClim 2.1 (Fick and 124 Hijmans 2017) for the locations where we collected seeds. We summarized historical data in 125 equivalent periods according to the time span between the ancestral and recent samples to avoid 126 biases from comparing unequal numbers of years. For instance, the timespan between the Western 127 ancestral (1991) and recent (2015) samples is 24 years, therefore, we defined the relevant period 128 leading to the ancestral population as going back 24 years in time. Hence, for the western samples we 129 compared climatic data within two periods: 1966-1990 (24 years) and 1991-2015 (24 years). 130 Similarly, given that the span between southern ancestral and recent samples is 16 years, we defined 131 the periods 1982-1998 (16 years) and 1999-2015 (16 years). The 1992 and 2010 sample from the 132 northern population are separated by 18 years so we compared the periods from 1973-1991 (18 years) 133 and 1992-2009 (18 years). Finally, we calculated mean climatic variables for the period comprised 134 betweeen northern 2010 and 2015 samples, although we did not perform comparisons in this case 135 because of the difference in variances due to unequal sample sizes. Following Dickman et al. (2019), 136 we also calculated deviations from the expected precipitation between 1975 and 2015 by subtracting 137 the 30-year mean precipitation from the average annual precipitation to identify departures from 138 climate normal, such as droughts (see supplementary material for more information on climatic 139 variables).

140 F0 Generation - Seeds were collected from ex situ seedbank conservatories following general 141 recommendations summarized in the ESCONET program (ENSCONET 2009). Briefly, seeds were 142 collected randomly from at least 50 mother plants within each population to maximize genetic 143 diversity. All seeds were stored ex situ in optimal conditions (low humidity and $5^{\circ} \mathrm{C}$ ), and they were 
144 used to generate the F0 generation for the common-garden experiment. On January 2016, we 145 resurrected 300 randomly sampled seeds from each temporal sample from the northern and western 1461991 populations, and 340 seeds from the southern temporal samples (Table S1). For each temporal 147 sample, we transplanted 50 randomly chosen plants to create the F1 generation. For the western 2015

148 population, we collected 50 randomly sampled seedlings from the exact same locations as the stored 149 seeds from 1991, to harvest seeds for the F1 generation. Hereafter, we refer to the groups of plants 150 from seeds sampled from the northern, central-western, and southern localities, as northern, western, 151 and southern populations (Figure 1A); and we referred to plants sampled in different dates as temporal 152 samples or 'ancestral' and 'recent' samples.

\section{Common-garden experiment}

156 The experiment was conducted in a common-garden in Montferrier-sur-Lez (South of France; $\left.15743^{\circ} 40^{\prime} 52.5468^{\prime \prime} \mathrm{N}, 3^{\circ} 52^{\prime} 31.9188^{\prime \prime} \mathrm{E}\right)$ in 2017 . To control for maternal and storage effects and to create a 158 family design for analysing plant traits on the F1 generation, we regenerated seeds through random 159 crosses within samples. The 50 plants in the F0 generation were randomly crossed (within samples) 160 using commercial bumblebees (Bombus terresris, Koppert Biological System) in insect-proof cages 161 during a 15-day period (Thomann et al. 2015). We set half-sib families using only one offspring per 162 capitula and assuming that the proportion of full-sibs from different capitula was negligible. We 163 studied 30 families each with 5 half-sibs resulting in circa 150 plants per each sampled year (nested 164 within population). Seeds were sowed on January $25^{\text {th }}, 2017$ in individual pots in a greenhouse. 165 Seedlings were transferred and planted on March $10^{\text {th }}, 2017$ for the northern and southern populations 166 and on March $13^{\text {th }}$ for the western population. In order to control for the environmental heterogeneity 167 inherent to a field experiment, the seedlings from different sampling dates were randomized within 168 populations in blocks consisting of 50 individuals (Figure S1-2). To facilitate experimental measures 169 and because we were mostly interested in temporal differentiation, plants were only randomized 170 within the population of origin (i.e., North, West and South).

\section{$171 \quad$ Plant traits}

172 We recorded growth-related, reproductive, and phenological traits for each plant in the F1 generation 173 to study differences between ancestral and recent samples in three populations. For each plant, we 174 measured rosette size on the day of transplantation (to the nearest $0.5 \mathrm{~cm}$ ), date of the first flowering, 175 capitula diameter (capitula size), and number of capitula. At the end of the experiment, plants were 176 harvested, and dry biomass was estimated as the total number of seed heads. We estimated number of 177 seeds and number of unpollinated florets to estimate seed set for the first three capitula. Individual 178 fitness was estimated by multiplying seed set by number of seed heads. Finally, to estimate pre- 
179 dispersal impact caused by predators. we inspected the harvested capitulas and recorded the presence

180 or absence of arthropods related to seed damage. We summarize this impact by estimating a "seed

181 predators' ratio" as the number of capitula infested.

182

Statistical analyses

We evaluated changes in climatic variables between temporal periods by performing paired t-tests. To characterize differences on plant traits between temporal samples, we analysed data separately for each population with linear (LMM) and generalized (GLMM) mixed effect models using the functions "lmer" and "glmer", implemented in the R package "Ime4" (Bates et al. 2014). The models included the family effect as a random factor nested in the fixed effect of sampling date. We performed LMM tests for rosette size, plant biomass, mean capitula size, and days to flowering. We implemented GLMM analyses for number of capitula using a Poisson distribution and a binomial distribution for seed set and presence of seed predators. To evaluate significance of the fixed effects, we used the Satterthwaite's method for linear models as implemented in the anova.lmerModLmerTest function in the R package "ImerTest" (Kuznetsova et al. 2017); and likelihood ratio tests for generalized models. We corrected for multiple comparisons using the Benjamini and Hochberg method (Benjamini and Hochberg 1995).

197 Phenotypic selection was estimated using linear $(\beta)$ and quadratic selection $(\gamma)$ gradients with classical multiple regression models of standardized traits on relative fitness (Lande and Arnold 1983). The highest-ranking models were used to estimate the selection gradients. We assessed the significance of the inferred $\beta$ and $\gamma$ terms by performing t-test with a null hypothesis of $\beta$ or $\gamma=0$. All phenotypic values were standardized prior to analyses. We tested phenotypic selection only for three traits: rosette size as a proxy of vegetative growth, days to flowering representing phenology, and mean capitula size for traits associated to pollinator attraction (Renoult et al. 2013).

All the models were validated by visual inspection of residual structure and homoscedasticity. The statistical analyses were performed in R 3.6.0 (R Core Team 2019).

Neutral and quantitative differentiation analysis Leaf material was collected from the mother plants (F0) of the common-garden experiment. DNA was

211 extracted using the CTAB method (Doyle and Doyle 1990) and genotyped at 10 microsatellite 212 markers designed for the cornflower (Le Corre et al. 2014). Neutral genetic differentiation (Nei's $F_{S T}$ ) 
213 between spatial and temporal samples was estimated using the R package "hierfstat" (Goudet 2015).

214 The $95 \%$ confidence interval (CI) of the $F_{S T}$ was estimating by bootstrapping 1,000 times across the

215 loci. We inferred a neighbour-joining tree comprising all temporal samples and calculated support for

216 the nodes using R packages "ape" (Paradis et al. 2004) and "hierfstat" (Jerome Goudet 2015). Note

217 that support for the nodes might be low because of factors such as incomplete lineage sorting and

218 gene flow. We calculated measures of genetic diversity such as the observed and expected

219 heterozygosity (Nei's genetic diversity) per temporal sample using the R package "adegenet" and

220 performed permutation tests to estimate confidence intervals (Jombart 2008).

221 To test whether quantitative trait differentiation was significantly different from neutral genetic 222 differentiation as a signature of natural selection, we compared $Q_{S T}$ and $F_{S T}$ values between temporal 223 samples for each population. The $Q_{S T}$ values for each trait between the temporal samples for each 224 population were defined following Thomann et al. (2015) as:

$$
Q_{S T}=\frac{\sigma_{\text {sample }}^{2}}{\sigma_{\text {sample }}^{2}+2 \sigma_{A}^{2}}, \text { with } \sigma_{A}^{2}=\frac{\sigma_{\text {fam }}^{2}}{2 \theta}
$$

where $\sigma_{\text {sample }}^{2}$ and $2 \sigma_{\text {fam }}^{2}$ are the between-sample and the among-family-nested within-sample variance of the quantitative traits, respectively, $\sigma_{A}^{2}$ is the pooled additive genetic variance of the two samples, and $\theta$ is the coefficient of coancestry. Given that families were composed of half-sibs we set $\theta$ to $1 / 8$. We used Linear Mixed Models (LMM) to partition the variance components for the $Q_{S T}$ analyses with both sampling year and family as random effects. The $95 \%$ confidence interval of the $Q_{S T}$ values were estimated by bootstrapping 1,000 times over families within each sample. The null hypothesis $\left(Q_{S T}=F_{S T}\right)$ was tested by comparing their $95 \%$ CI's. $Q_{S T}$ was considered significantly different from $F_{S T}$ when the two $95 \%$ CI's did not overlap or overlapped marginally with point $Q_{S T}$ estimates outside $F_{S T}$ bootstrapping range.

Results

Climatic variation and temporal changes in traits, seed set, and seed predators

Precipitation was lower than average for the year of collection of all recent samples (2015) across all populations (Figure 1B). The climate leading up to the year of collection for the western 1991 ancestral sample, was severely drier than average (Figure 1B). The southern population experienced the greatest variation in precipitation and a long drought from 2002 to 2007 (Figure 1B). Consistent with climate change, temperature increased between periods at the localities of the three populations (Figure 1C, Table S6). 
246 Germination rates for the different accessions of the F0 and F1 plants where $>70 \%$ and $>91 \%$,

247 respectively. Germination date in the F0 generation did not differ significantly between dates for the

248 northern and southern samples (Table S2, Figure S3). However, plants from the recent western sample

249 germinated on average one and half day later compared to the 1991 sample (Table S3, Figure S3).

250 Ancestral and recent samples showed significant and divergent differences across populations for 251 rosette size, flowering date, capitula size, and seed set (Table S2, Figure 2). Rosette size was different 252 between dates for the northern and southern populations, and the trend of the evolutionary change was 253 directional, although following opposite directions: while plants in recent northern population are 254 smaller, rosette size in the southern population increased over time (Table S2, Figure 2A, C). In 255 contrast, days to flowering was different between temporal samples only for the western populations, 256 whereby recent individuals flowered on average 6 days earlier (Figure 2E).
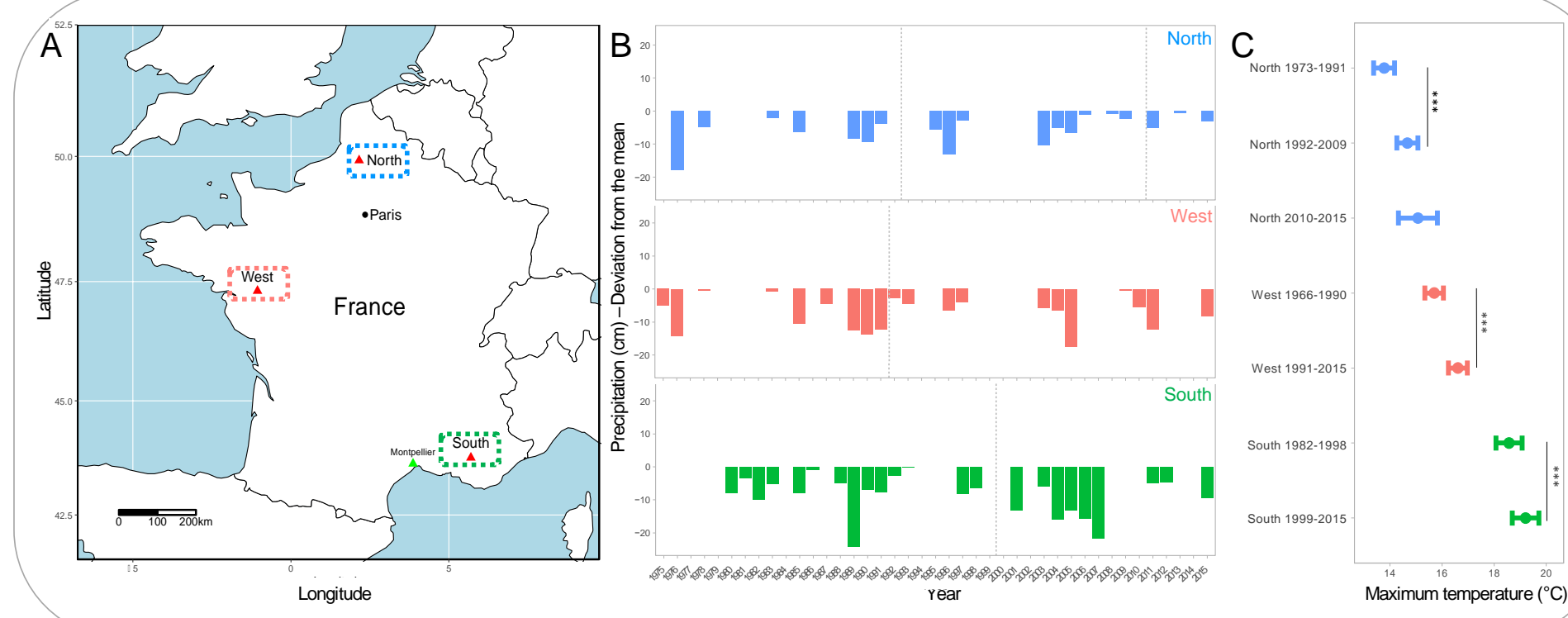

257

258 Figure 1. Sample locations and climatic variables; precipitation showed no trend with time across populations' localities,

259 while temperature has increased over time in all localities. A. Map of seed collection sites from northern, western, and

260 southern populations of Cyanus segetum in France. B. Precipitation (cm) at the northern, western, and southern locations

261 over the 30 years preceding the year of collection of the most recent temporal sample. Vertical bars correspond to

262 precipitation deviation $(\mathrm{cm})$ from the 30-year average. C. Maximum temperatures $\left({ }^{\circ} \mathrm{C}\right)$ at the northern, western, and southern

263 locations summarized over periods of time according to the time span between the ancestral and recent temporal samples.

264 Significance codes: p-value $<0.0001^{\prime * * * 1},<0.01^{\prime * * 1}, 0.01-0.05^{\prime *}$. Horizontal lines correspond to the standard error.

265 We found divergent evolution of capitula size in western and southern populations: the recent sample 266 from the South exhibited larger capitula size and outperformed the ancestral sample having a higher 267 seed set and lower infestation by seed predators (Table S2, Figure 2I). Conversely, the recent sample 268 from the West had smaller capitulas and lower fitness in terms of seed set and biomass compared to 
269 the ancestral, yet it showed a lower proportion of attacks by seed predators (Table S2, Figure 2).

270 Similarly to groups of seed predators found in other cornflower populations (Koprdova et al. 2015),

271 the most abundant seed predators were larvae of Cecidomyiidae (gall midges). We also found species

272 of Tephritidae (fruit flies), Tortricidae (leafroller moths), Curculionidae (weevils), and parasitoid

273 wasps.

274 The spatial block had a pervasive effect on most measured traits (Table S2, Figure S2, S4). In 275 particular, the block, as well as the interaction between sampling date and block, had a strong effect 276 on condition-related estimates such as number of capitula, biomass, seed set, and seed predators ratio 277 across all populations (Table S2, Figure S2). On average, blocks closer to the edges in the northern 278 and southern populations presented higher seed set (Figure S2), while biomass was lower in the edges 279 of the experimental field (Figure S2-3). Since we measured rosette size before transplantation, we 280 were able to compare values across the three different latitudinal samples. We found that the 281 population of origin had a significant impact on rosette size; the southern population showed smaller 282 rosette size $(12.89 \pm 0.15 \mathrm{~cm})$ than the northern $(15.43 \pm 0.14 \mathrm{~cm})$ and western $(15.35 \pm 0.16 \mathrm{~cm})$ 283 populations $(\mathrm{F}=75.4, \mathrm{DF}=2$, $\mathrm{p}$-value $<0.0001)$, which did not diverge among them. Although days 284 to flowering was affected by our block design primarily within the western population, we were able 285 to contrast this trait throughout latitudinal populations (Table S2, Figure S2). We showed that date of 286 flowering is different for all the populations with southern populations blooming first, followed by the 287 western, and finally by the northern samples (Figure S2). 
North
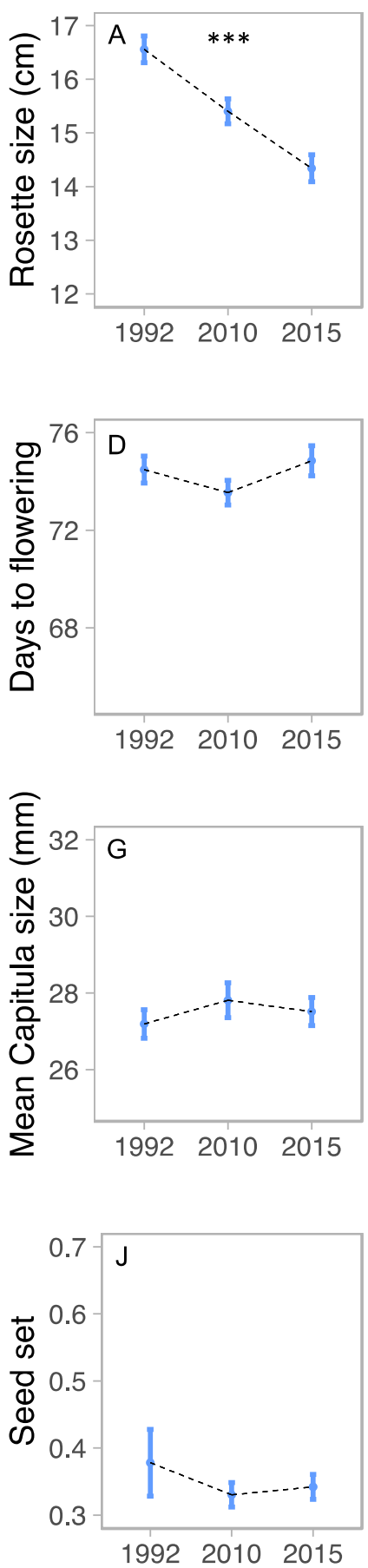

West
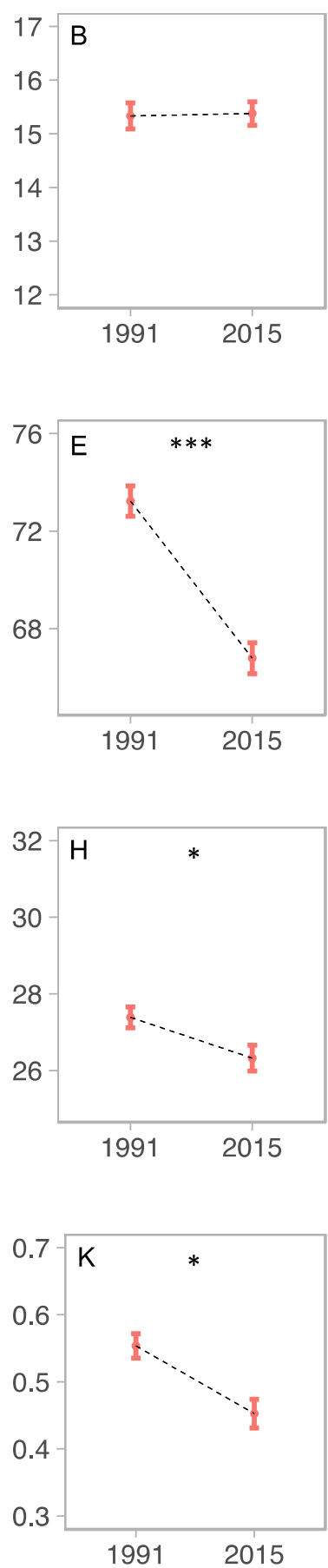
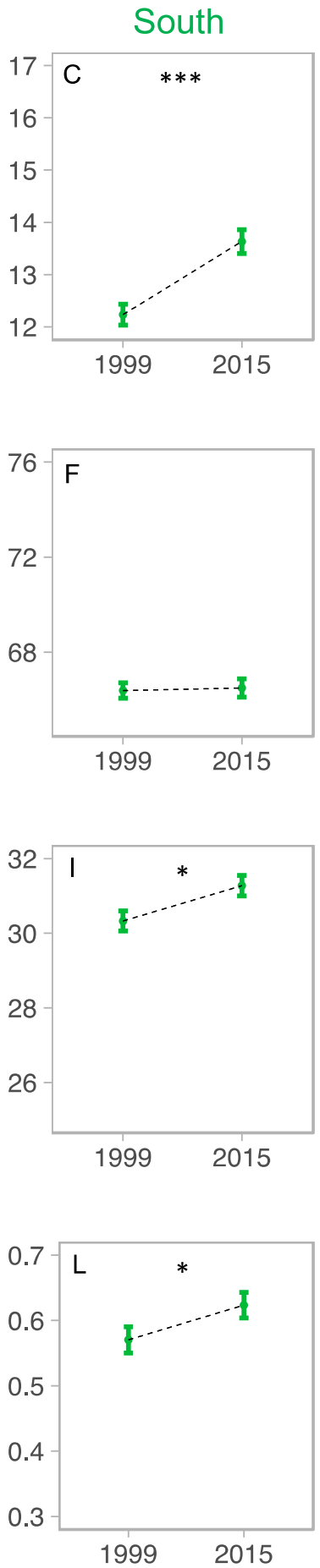

Figure 2. Phenotypic changes between ancestral and recent samples exhibited divergent trends for rosette size, days to flowering, and mean capitula size across three populations along a latitudinal gradient in France. Seeds were resurrected from a northern (North), central-western (West), and southern (South) population and traits were measured in a common garden experiment. A-C. Rosette size (cm). D-F. Mean Capitula size (mm). G-I. Days to flowering from germination. J-L. Mean seed set (a proxy for fitness). Significance codes: p-value $<0.0001^{\prime * * *},<0.01^{\prime * * 1}, 0.01-0.05^{\prime *}$. Vertical lines correspond to the standard error. 
299 We found moderate correlations between most of the traits for the temporal samples within 300 populations, including plant size, mean capitula size, biomass, and number of capitula (Table S4). The 301 strongest

302 phenotypic correlation was between biomass and number of capitula throughout all populations, with 303 values ranging from 0.821 to 0.902 .

305 Finally, all significant effects remained significant after Benjamini and Hochberg correction for multiple testing except mean capitula size in the southern population, which was marginally significant ( $\mathrm{p}$-value $=0.052$, Table S2) suggesting moderate evidence for this shift.
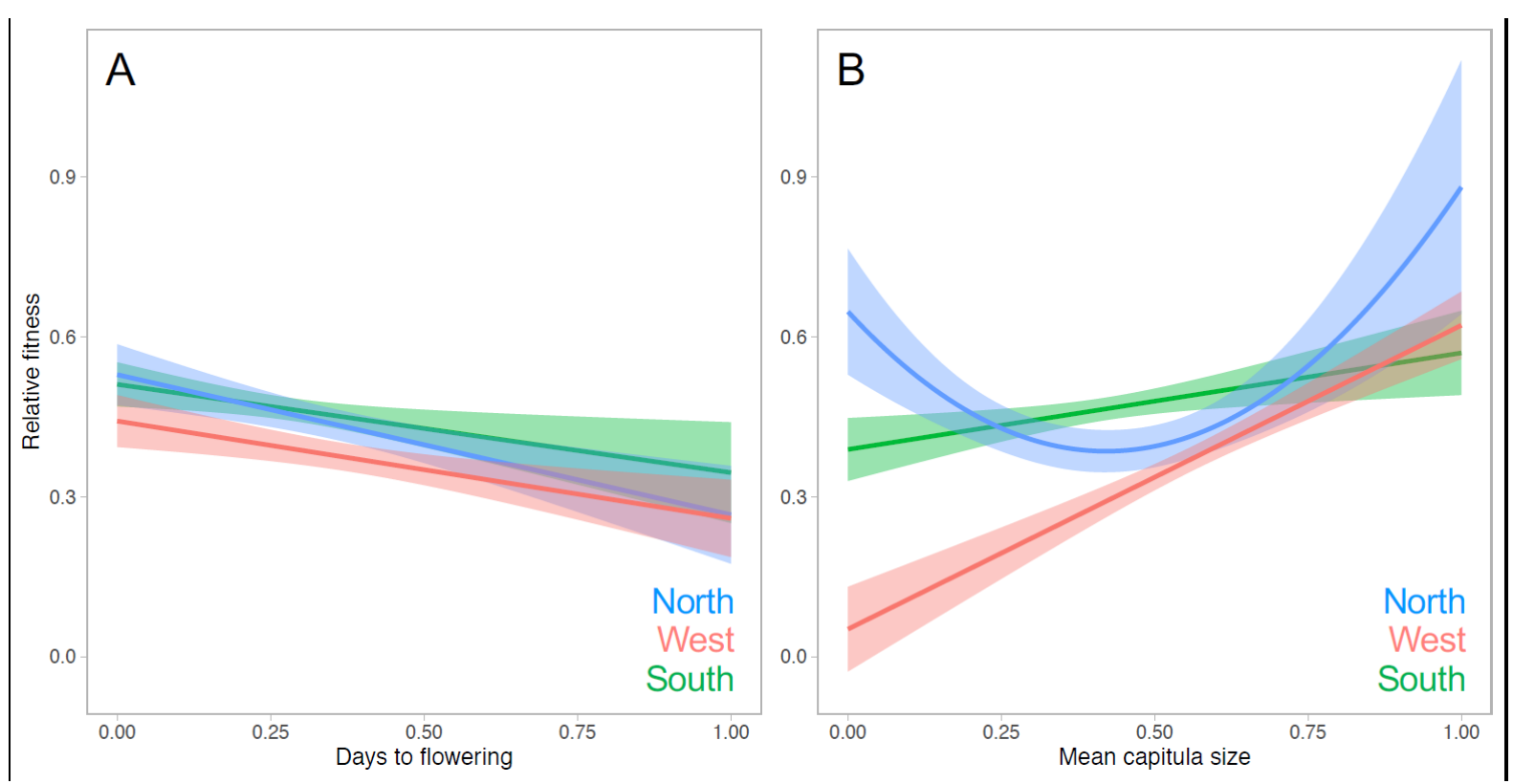

Figure 3. Earlier flowering and larger capitula size are correlated with higher fitness. Graphs depict the relationship between average flowering date and mean capitula size versus fitness measured in the common garden experiment in southern France. Selection gradients were inferred estimating fitness as mean seed set multiplied by number of capitulas and by fitting regression models using maximum likelihood methods. Shaded areas indicate the standard deviation.

\section{Strength of selection on phenotypic traits}

318 Phenotypic selection analysis at the experiment location with a natural community of pollinators 319 indicated that reproductive traits were significantly correlated with fitness (Table 1). We found negative linear selection gradients for days to flowering across all populations indicating that earlier flowering led to higher fitness (Figure 3A). Similarly, plants with larger capitula sizes showed higher fitness, though selection is disruptive on the northern population $(\gamma=0.518, p<0.0001$, Figure $3 B)$. Within populations, we found directional selection for larger capitulas in the ancestral samples from 
324 the southern 1999 sample, while for the recent 2015 sample, selection on capitula size was not 325 significant (Table 1). In contrast, in the western population, there was strong positive selection for 326 bigger flowers on both temporal samples with the strength of selection being higher on the recent 3272015 population, which shows a lower mean capitula size compared to the ancestral 1991 (Table 1). 328 Notably, selection for larger capitulas was stronger for the sampling dates with smaller capitulas in both western and southern populations.

330

331 In all our regression models, the inclusion of multiple predictors had only a slight influence on the $\beta$ 332 and $\gamma$ terms, with no change in the estimated direction of selection, suggesting that selection is mostly 333 acting on individual traits.

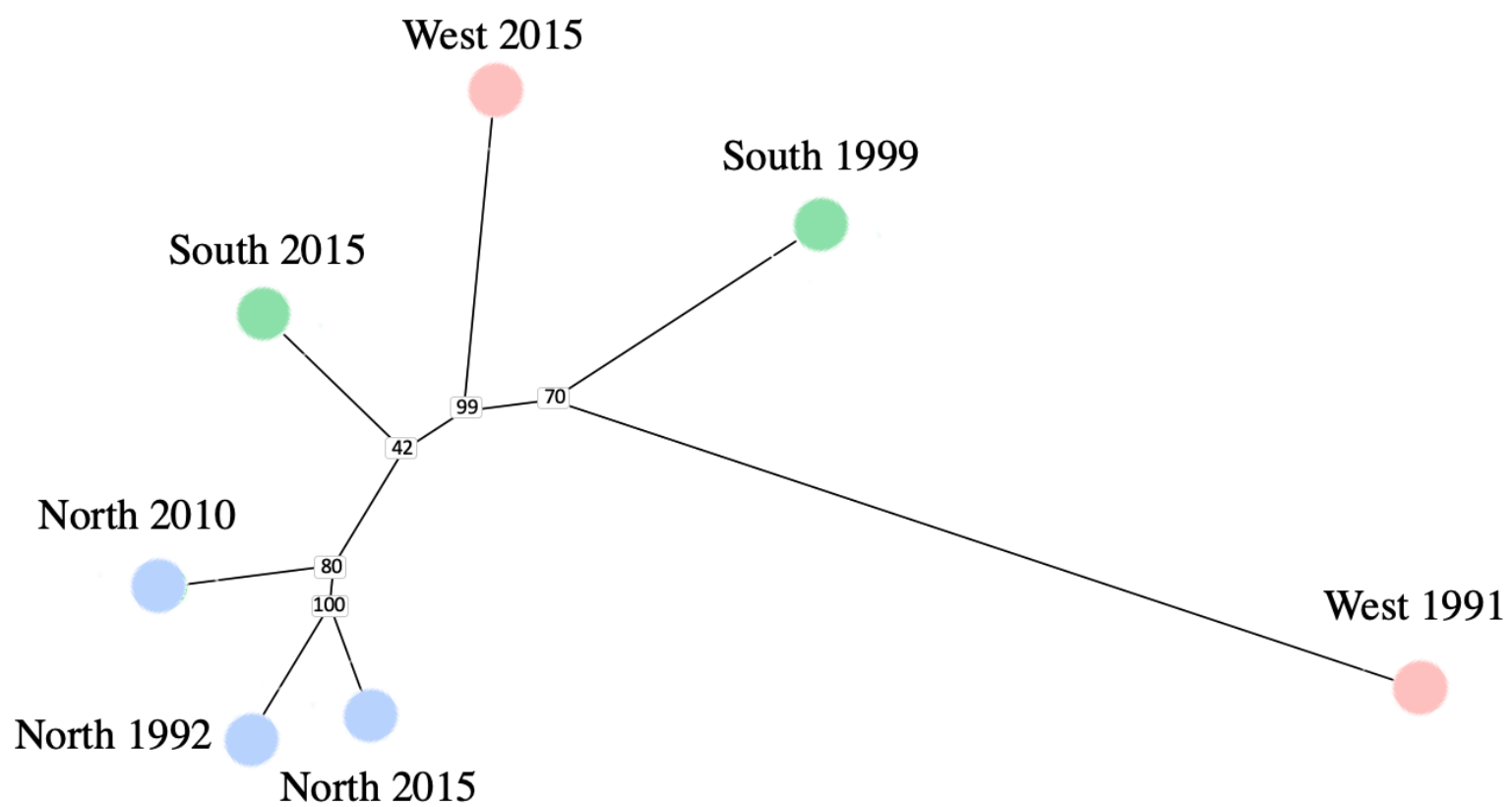

Figure 4. Neighbour-joining tree based on raw pairwise $F_{S T}$ estimates from microsatellite markers among temporal samples from the different populations. Numbers at nodes denote bootstrap support. Blue, northern population; red, western population; and green southern population.

Neutral genetic differentiation between temporal samples and among populations

343 All populations and temporal samples exhibit high levels of genetic diversity, which did not significantly differ across temporal samples and populations (Table S1). Global $F_{S T}$ values suggested moderate differentiation between populations (Figure 4, Table S5). Comparisons between the Northen temporal samples showed lower $F_{S T}$ values $\left(F_{S T}\right.$ ranged from 0.015 to 0.036$)$ compared to any other 
western or southern samples ( $F_{S T}$ ranged from 0.042 to 0.1391 ), supporting genetic continuity of the

348 northern samples across the three sampling dates. In contrast, ancestral and recent samples from the

349 West and the South clustered together and showed a higher genetic affinity by temporal sample than

350 by sampling origin (Figure 4, Table S5). Unexpectedly, the western 2015 sample showed the lowest

351 differentiation with the southern $2015\left(F_{S T}=0.067[0.004,0.094] 95 \% \mathrm{CI}\right)$. By contrast, although the

352 western 1991 sample showed the lowest $F_{S T}$ with the northern $1992\left(F_{S T}=0.1232[0.083,0.167] 95 \%\right.$

$353 \mathrm{CI}$ ), it seemed highly differentiated from all the other temporal samples. Thus, suggesting high levels

354 of ancestral as well as ongoing asymmetrical gene-flow across populations (Figure 4, Table S5).

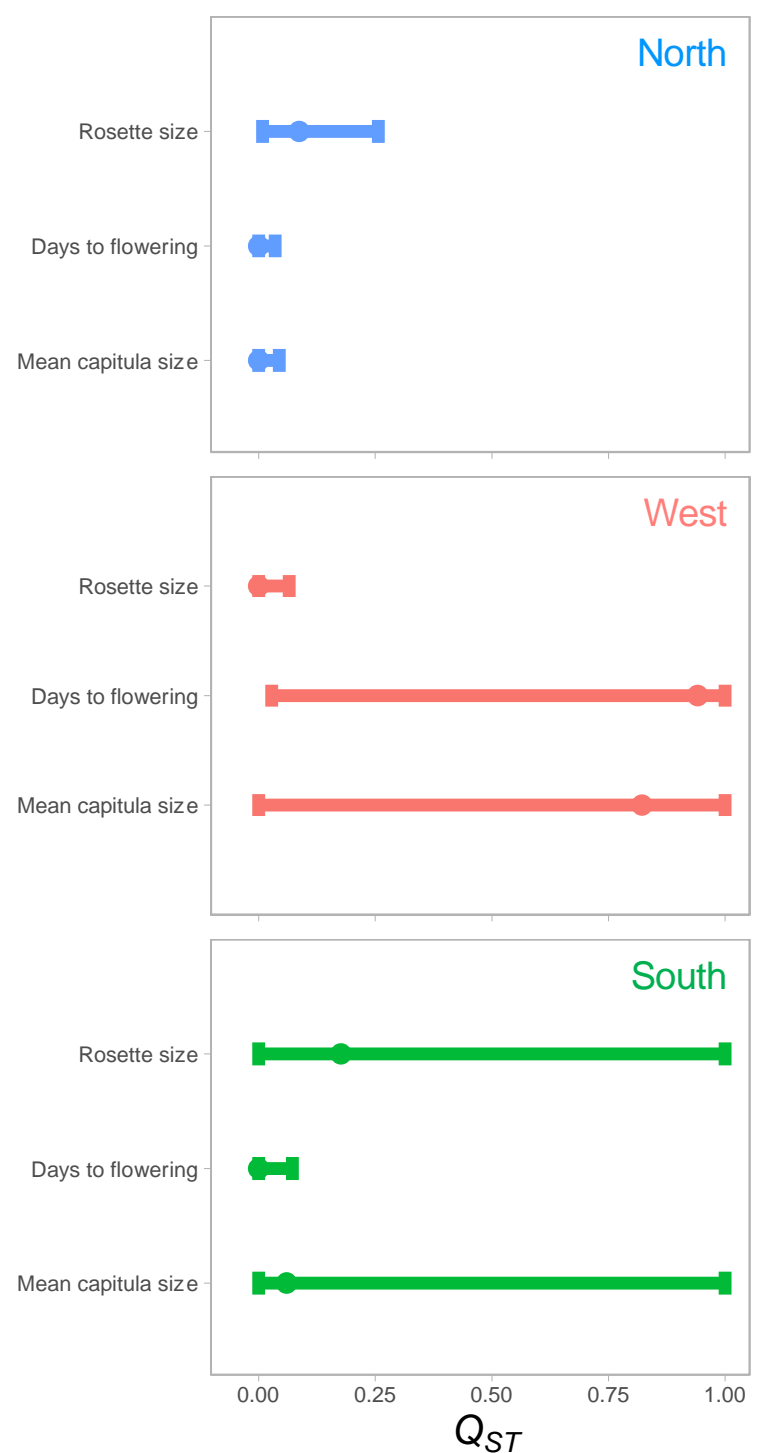

Figure 5. Natural selection played a role shaping some of the observed distributions of traits of ancestral and recent samples. represent the estimated $Q_{S T}$ between the ancestral and recent samples from northern, western, and southern populations with their $95 \%$ confidence intervals (CI). The grey shade represents the $F_{S T} 95 \%$ CI estimates. 
364 Comparisons of $F_{S T}$ and $Q_{S T}$ estimates for the different traits indicated a significant role of selection

365 for some traits between the ancestral and recent samples (Figure 5). $Q_{S T}$ point estimates were higher

366 than the $F_{S T} 95 \%$ CI for rosette size in the North and the South, and days to flowering and mean

367 capitula size in the West, thus suggesting moderate evidence for divergent selection on these traits

368 (Figure 5). Contrariwise, the $Q_{S T}$ for rosette size in the West was significantly lower than the $F_{S T}$,

369 pointing towards stabilizing selection maintaining similar values of this trait (Figure 5). Of note, $Q_{S T}$

370 point estimates for days to flowering $\left(Q_{S T}=0.969\right)$ and capitula size $\left(Q_{S T}=0.902\right)$ for the western

371 population were remarkably high ( $Q_{S T}$ values $>0.7$ are considered high, see (O'Hara 2005)) although

372 the CI basically spanned the entire range of possible values. In the South, the empirical $Q_{S T}$ point

373 estimate for mean capitula size was slightly higher than the point $F_{S T}$ estimate, yet this trait showed a

374 wide confidence interval, similarly to other traits with higher $Q_{S T}$ point estimates. All remaining traits

375 showed lower $Q_{S T}$ point values than the $F_{S T}$ estimates (Figure 4).

Table 2. The linear $(\beta)$ selection gradients and quadratic $(\gamma)$ selection gradients for plant traits per temporal sample and population. (ns: not significant $\mathrm{p}>0.010, \dagger \mathrm{p}<0.10,{ }^{*} \mathrm{p}<0.0,{ }^{* *} \mathrm{p}<0.01, * * * \mathrm{p}<0.001$ )

\section{Discussion}

384 We resurrected seeds from ancestral and recent samples of Cyanus segetum across populations at different latitudes to document plant trait evolution. The stored and recent seeds were separated by a span of about two decades, characterized by a relentless escalation of various global change components. By growing ancestral and descendant seeds in a common environment, we showed divergent evolution in plant size and capitula size for different locally adapted populations and a shift in flowering date between ancestral and recent samples from western France. Importantly, the similarity between neutral genetic diversity estimates across temporal samples suggests that genetic drift is not the sole driver of the shifts observed. We documented selection gradients for earlier 
393 flowering, indicate that natural selection may have played a role in triggering some of these 394 phenotypic changes over time. Thus, our results outline the rapid pace of evolution shaping the 395 trajectories of natural populations across local spatial gradients and the potential for adaptation of 396 populations facing global change through contemporary evolution.

Is the evolution of plant traits across populations consistent with global change?

398 Rosette size evolved in different directions in the northern and southern populations: while it steadily 399 decreased over time in the North, it increased in the South. We found moderate evidence that these 400 divergent shifts were driven by natural selection with point $Q_{S T}$ estimates higher than the $F_{S T}$ 401 confidence intervals. These idiosyncratic changes in face of warming are likely related to the 402 inconsistent impact of global change across latitudes. Increases in leaf size in southern warmer 403 habitats have frequently been demonstrated (Royer et al. 2005; Niinemets et al. 2007; Tng et al. 404 2013). These studies agree with predictions from simulation experiments suggesting that variations in 405 leaf size along a climatic gradient result from greater evaporative demand of larger leaves due to 406 enhanced thickness of the boundary layer for energy and gaseous exchange (Niinemets et al. 2007).

407 Yet, reduced plant size and leaf size have also been observed in response to pronounced droughts 408 (Eziz et al. 2017). An increase in plant size in the South is nonetheless consistent with a mechanism to 409 cope with the escalation of high temperatures in the Mediterranean (Harpaz et al. 2014).

410 Additionally, severe droughts in southern France in the first decade of the twenty-first century may 411 have hindered increase in plant size (Figure 1B), suggesting that the observed increase is likely the 412 result of recent selection over the last ten years when precipitation has been, overall, higher than 413 average (Figure 1B). Larger plant size might constitute a fast-growing strategy to reach minimum 414 sizes for early flowering, as apparently indicated by the negative correlation between onset of 415 flowering and plant size we found only for the southern population. Similarly to this result, Sun and 416 Frelich (Sun and Frelich 2011) showed a negative correlation between growth rate and flowering 417 onset across 25 herbaceous plants, hinting at a fast-growth, flower-early strategy; which might also be 418 the case of the cornflower in the southern population. The steady decrease in rosette size in the 419 northern population can be interpreted as the result of warming with non-limiting precipitation. In 420 such context, selection for a fast-growing strategy is relaxed, resulting in reduced size of seedlings. 421 This is consistent with the positive and non-significant selection gradient for rosette size in the 422 northern population.

424 We observed a latitudinal gradient for flowering onset with northern populations flowering later than 425 southern ones, closely resembling the temporal patterns of the plant communities in these latitudes 426 (Rhoné et al. 2010). In annual plant species as the cornflower, flowering time is a major adaptive trait 
because it synchronizes the initiation of reproduction with favourable environmental conditions and is expected to respond rapidly to latitudinal changes (Rhoné et al. 2010). In northern populations, where winters are colder and frost may still occur during spring, plants flowering too early are exposed to

430 frost damage, whereas in southern populations, plants flowering exceedingly late could suffer from 431 heat and drought stress in early summer (Rhoné et al. 2010). Besides the expected latitudinal gradient 432 in floral phenology, we found heterogeneous flowering date shifts among temporal samples. 433 Flowering has become earlier only for the western population whereby the recent sample flowered, on 434 average, six days before the ancestral. Remarkably, $Q_{S T}$ estimates moderately supported the role of 435 divergent selection triggering this shift in the western population.

436 Regardless of the population and dates, selection gradients showed that earlier flowering resulted in 437 higher fitness at the warmer southern location where the experiment was carried out. The earlier 438 blooming of spring-flowering species is a well-characterized response to climate warming because 439 flowering is especially sensitive to temperature changes (Abu-Asab et al. 2001; Fitter and Fitter 440 2002). Explicitly, advances in first flowering is directly correlated with an increase in minimum 441 temperatures (Abu-Asab et al. 2001; Fitter and Fitter 2002; Nevo et al. 2012; Dijk and Hautekèete 442 2014) and minimum temperatures have significantly increased for all locations (Table S6). 443 Nevertheless, the widespread trend of selection for earlier flowering, although consistent with global 444 change and life history theory, can be misleading if the trait is condition-dependent, flowering 445 duration is unaccounted for, or not all fitness elements are considered (Austen et al. 2017). Flowering 446 date in self-incompatible species like the cornflower can also be constrained by pollinator emergence, 447 which is expected to be a primary factor shaping the evolution of early flowering. In addition, given 448 the low level of genetic differentiation between the western 2015 and Southern 2015 samples, and 449 their similitude in mean flowering date, we cannot rule out a contribution of migration from 450 populations locally adapted to southern latitudinal selection regimes into the advance in flowering 451 date observed for the western population. Likewise, a shift towards earlier floral phenology could 452 have contributed to greater synchronization between western 2015 and southern 2015 populations, 453 thus facilitating gene-flow. This hypothesis is also supported by studies showing that human454 transportation of seeds is a major factor reshuffling genetic variation in natural populations of $C$. 455 segetum in France (Le Corre et al. 2014).

456 Capitula size exhibited shifts over time and was the main trait associated with fitness across temporal 457 samples and populations. Selection gradients between temporal samples measured in southern France 458 indicated that selection was stronger for ancestral samples, as well as for samples with smaller 459 capitulas. Capitula size (flower size) plays a key role in pollinator attraction and seed set 460 (Parachnowitsch and Kessler 2010; Gervasi and Schiestl 2017). Because seed set has been shown to 461 positively correlate to capitula size in the cornflower (Thomann, 2014), we assume that the strong 
positive relationship between larger capitulas and fitness observed in our experiment was driven by

463 pollinators. Indeed, pollinators can drive adaptive evolution for traits that maximize their attraction

464 and subsequent pollen delivery (Gervasi and Schiestl 2017). Particularly, pollinators select for larger

465 flowers because they are more conspicuous and may be associated with greater rewards (Blarer et al.

466 2018). For instance, Parachnowitsch and Kessler (2010) manipulated the effect of pollinator on fitness

467 through hand pollination and compared phenotypic selection in open- and hand-pollinated plants.

468 They found that natural selection was significantly stronger in the open-pollinated plants and that 469 hand pollination removed directional selection for larger flowers (Parachnowitsch and Kessler 2010).

470 It is thus likely that decreases in pollinators abundance, namely pollinator decline, have driven the 471 evolution of capitula size in the cornflower; although this remains to be tested empirically via 472 experimental manipulation of pollinator availability. Martin et al (2019) have reported declines in 473 pollination services in France based on reductions in pollinator-dependant crop yield. Surprisingly, in 474 the face of pollinator decline, temporal evolution of this trait was not convergent across populations, 475 although bigger capitulas were correlated with higher fitness. In fact, we found moderate evidence 476 that mean capitula size has decreased in the western population while increased over time in the 477 southern population. Conversely, in the northern population, while Thomann et al. (2015) reported a 478 significant increase in capitula size between 1992 and 2010 (using the same seed lots but conducting 479 an in situ greenhouse experiment), we report the same trend here although no statistically significant. 480 The failure to recover the changes reported by Thomann et al. (2015) is likely associated with the 481 higher variance in the phenotypic traits introduced by our field experiment due to an a priori bias in 482 the plastic responses of the non-locally adapted populations from northern and western France 483 (Whitlock 2008a; Rhoné et al. 2010).

485 In addition to the variance introduced by the field experiment, there were phenotypic differences 486 between the spatial blocks, which suggest that pollination, competition, or resources may have 487 differed at a fine scale in the field (Table S3, Figure S2, S4). Higher seed set closer to the edges might 488 reflect increased accessibility to foraging pollinators. Contrariwise, since competition is expected to 489 have played a minor role given that plants were separated by a meter, decreases in plant size towards 490 the edges may be the result of higher wind exposure. Besides germination and rosette size, which 491 were measured before transplantation, we were not able to make comparisons of trait values across 492 different populations to explore for signatures of local adaptation since we only randomized within 493 populations (Figure S1). Several studies have shown that heterogeneities among blocks mostly alter 494 plastic responses but not the direction of the evolutionary change, which can still be detected. For 495 instance, through a resurrection experiment, Frachon et al. (2017) grew Arabidopsis thaliana seeds 496 collected across an 8-year period in six micro-habitats with different soil and competition conditions 
representative of the local populations (Frachon et al. 2017). They found that evolution of the 498 phenotypic traits towards either higher or lower values was consistent across micro-habitats, though 499 the underlying genetic basis and the strength of the significance varied (Frachon et al. 2017). We

500 therefore regard as unlikely that the microhabitat conditions of the terrain have affected the direction 501 of the evolutionary change that we report but presumably only its significance. Within our findings of 502 increased capitula size in the South, and the previous experiment using seeds from the northern 503 locality (Thomann et al. 2015), is nested the possibility of a general trend towards larger floral display 504 over time. A reciprocal transplant design, instead of a common garden experiment restricted to one 505 locality, would have allowed us to test population-specific adaptation across the sample locations to 506 assess whether fitness of the recent samples was indeed higher in their habitats. Additional refinement 507 of the experiment to include a pollinator community under controlled conditions across all the studied 508 localities might improve our understanding of the influence of local factors into the characterization 509 of convergent/divergent evolution of the phenotypic traits and the adaptive value of these changes.

510 Self-incompatible plant species facing pollinator decline, are expected to increase flower size or other 511 traits related to floral display to enhance pollinator visitation (Thomann et al. 2013). Gervasi et al. 512 (2017) conducted real-time experiments showing that populations pollinated by bumblebees evolved 513 larger plants and flowers in only six generations. Since the cornflower is a self-incompatible that 514 entirely relies upon pollinators for fertilization, evolution towards showier capitulas might be 515 associated with the pollinator-poor environments caused by the widespread increase in habitat 516 destruction, pesticide use, light pollution, and other components of global change fostering declines of 517 pollinator communities (Brys and Jacquemyn 2012; Thomann et al. 2015). Given that short-term 518 evolution towards self-compatibility is rare among plants, the evolution of reinforced interactions with 519 pollinators can be considered as one of the main adaptive mechanisms for outcrossing species like $C$. 520 segetum under pollinator decline (Thomann et al. 2013). However, Ramos and Schiestl (2019) have 521 revealed that higher degrees of self-compatibility in Brassica rapa can evolve by experimentally 522 manipulating pollinator abundance, which highlights differences in evolutionary trajectories 523 depending on species and the genetic architecture of the self-incompatible system. Moreover, floral 524 signals used for pollinator attraction can also be perceived and used by other organism making 525 reproductive traits particularly vulnerable to conflicting selection (Strauss and Irwin 2004; Raguso 526 2018). For example, antagonists such as herbivores and pre-dispersal seed predators can also exert strong selection on floral traits (Strauss and Irwin 2004). Notably, in the northern population, bigger 528 capitulas are seemingly related to higher fitness after intermediate capitula sizes, and there seems to 529 be a trade-off at further increases in capitula size, which might be explained in part by a higher extent 530 of seed predators. Moreover, conflicting selection may contribute to explain the fact that the recent 531 western population evolved towards smaller capitula size but had a lower rate of infestation compared 532 to the ancestral one. Accordingly, we do not rule out that seed predators may have played a part 
533 triggering this seemingly maladaptive shift towards smaller capitulas resulting in lower rates of seed

534 predator infestation in spite of compromising pollinator visitation.

536 A common finding is that measures of genetic variance are increased in novel environments causing $537 Q_{S T}$ estimates to be too low (O'Hara 2005a; Whitlock 2008b). Consequently, identifying traits for 538 which $Q_{S T}$ is significantly different from $F_{S T}$ has proven to be extremely difficult for studies that 539 consider less than ten populations (O'Hara 2005a; Whitlock 2008b; Leinonen et al. 2013). The impact 540 of the number of sampled populations in the estimation of $Q_{S T}$ seems to be particularly problematic 541 for its use to test for natural selection in in situ resurrection experiments, whereby usually two 542 temporal samples of a population are compared (Franks et al. 2008b). Furthermore, the bias in the 543 estimation of $Q_{S T}$ confidence intervals is appreciable when $Q_{S T}$ true values are high $\left(Q_{S T}>\sim 0.7\right)$ 544 (O'Hara 2005b). Therefore, we do not rule out that selection has played a role in the changes on 545 rosette size, date of flowering, and capitula size across populations where the $Q_{S T}$ true estimate was 546 higher than the $F_{S T}$ CI, especially for days to flowering and capitula size in the western population 547 whereby $Q_{S T}>0.9$.

549 Can evolution contribute to population viability of species facing global change?

550 On-going resurrection projects represent an exciting opportunity to test whether contemporary evolution is mitigating the impact of global change on plant demography, possibly rescuing populations from extinction (Franks et al. 2008a). For outcrossing species, shifts in flowering time and evolution towards reinforced interactions with pollinators have been predicted as the primary evolutionary changes rescuing populations facing global pollinator decline (Thomann et al. 2013). We uncovered evolutionary shifts in pollinator attractive traits such as capitula size, which was linked to higher fitness for some populations. However, we did not observe a clear signature of fitness maximization over time despite evolution across all studied populations. Migration load due to high gene flow between western and southern populations might help explain the maladaptation of the western 2015 sample. This recent western sample not only showed later germination and earlier flowering but also a smaller capitula size, lower biomass, and seed set compared to the ancestral; thus, seemingly evolving away from a fitness peak. Theoretical models and empirical evidence show that gene-flow imposes a limit on local adaptation, and may foster evolutionary change in a direction opposite to natural selection, resulting in a population sub-optimally adapted (Lenormand 2002). However, the experiment was conducted in the South of France, which undermines the unique role of gene-flow shaping this pattern. 
567 optimization. In particular, traits for which we report evolutionary change are presumably under 568 frequency-dependent selection, whereby there is no optimization principle to predict the outcome of 569 adaptive evolution (Ferriere and Legendre 2012). For instance, early flowering individuals will be rare 570 since most conspecific plants have not yet flowered, and given that many pollinators prefer to forage 571 in common phenotypes, these earliest bloomers can be easily skipped (Forrest and Thomson 2009).

572 Contrastingly, the advantage of phenotypes with increased plant or flower size is higher when rare or 573 in low-density populations (Jacquemyn et al. 2012). Nonetheless, it is hard to disentangle the effects 574 of frequency-dependent selection from migration load and drift, and temporal data along with 575 theoretical models will provide insights into the evolutionary dynamics of these reproductive traits in 576 C. segetum.

577 In summary, we have shown rapid evolution of growth-related and reproductive traits. Notably, 578 patterns of evolution are not convergent across traits and latitudes. Although compelling evidence of 579 the adaptive nature of most of these trait shifts remains elusive, they are consistent with widespread 580 documented responses to global change and might represent putative cases of evolutionary rescue. 581 Nonetheless, testing for evolutionary rescue would entail linking these observed rapid changes to 582 populations escaping the fate of extinction, which involves collecting additional demographic data 583 through long-term monitoring of the populations in the field. Indeed, there is a wealth of possible 584 feedback scenarios that can only be assessed by studying evolution in situ. Therefore, field 585 experiments testing for contemporary evolution should be higher on the research agenda due to the 586 importance of predicting evolutionary trajectories of natural populations in realistic environments 587 under the pressing impacts of global change.

\section{References}

590 Abu-Asab, M. S., P. M. Peterson, S. G. Shetler, and S. S. Orli. 2001. Earlier plant flowering in spring as a response to global warming in the Washington, DC, area. Biodiversity

Albrecht, H., J. Cambecèdes, M. Lang, and M. Wagner. 2016. Management options for the conservation of rare arable plants in Europe. Botany Letters 163:389-415. Taylor \& Francis.

Antonovics, J., A. D. Bradshaw, and R. G. Turner. 1971. Heavy Metal Tolerance in Plants. Pp. 1-85 in J. B. Cragg, ed. Advances in Ecological Research. Academic Press. 
Austen, E. J., L. Rowe, J. R. Stinchcombe, and J. R. K. Forrest. 2017. Explaining the apparent paradox of persistent selection for early flowering. New Phytol 215:929934.

Bates, D., M. Mächler, B. Bolker, and S. Walker. 2014. Fitting Linear Mixed-Effects Models using lme4.

Benjamini, Y., and Y. Hochberg. 1995. Controlling the False Discovery Rate: A Practical and Powerful Approach to Multiple Testing. Journal of the Royal Statistical Society. Series B (Methodological) 57:289-300. [Royal Statistical Society, Wiley].

Blarer, A., T. Keasar, and A. Shmida. 2018. Possible Mechanisms for the Formation of Flower Size Preferences by Foraging Bumblebees. Ethology 108:341-351.

Bodbyl Roels, S. A., and J. K. Kelly. 2011. Rapid evolution caused by pollinator loss in Mimulus guttatus: rapid evolution after pollinator loss. Evolution 65:2541-2552.

Brys, R., and H. Jacquemyn. 2012. Effects of human-mediated pollinator impoverishment on floral traits and mating patterns in a short-lived herb: an experimental approach: Human-mediated pollinator impoverishment selects for autonomous selfing. Functional Ecology 26:189-197.

Chambres d'agriculture des Pays de la Loire. 2013. Panorama socio-économique de l'agriculture des Pays de la Loire Données régionales et spécificités départementales.

Cheptou, P.-O., O. Carrue, S. Rouifed, and A. Cantarel. 2008. Rapid evolution of seed dispersal in an urban environment in the weed Crepis sancta. Proceedings of the National Academy of Sciences 105:3796-3799.

Dickman, E. E., L. K. Pennington, S. J. Franks, and J. P. Sexton. 2019. Evidence for adaptive responses to historic drought across a native plant species range. Evolutionary Applications 12:1569-1582. 
622

623

624

625

626

627

628

629

630

631

632

633

634

635

636

637

638

639

640

641

642

643

644

645

646

Dijk, H. V., and N.-C. Hautekèete. 2014. Evidence of genetic change in the flowering phenology of sea beets along a latitudinal cline within two decades. Journal of Evolutionary Biology 27:1572-1581.

Eziz, A., Z. Yan, D. Tian, W. Han, Z. Tang, and J. Fang. 2017. Drought effect on plant biomass allocation: A meta-analysis. Ecology and Evolution 7:11002-11010.

Ferriere, R., and S. Legendre. 2012. Eco-evolutionary feedbacks, adaptive dynamics and evolutionary rescue theory. Philosophical Transactions of the Royal Society B: Biological Sciences 368:20120081-20120081.

Fick, S. E., and R. J. Hijmans. 2017. WorldClim 2: new 1-km spatial resolution climate surfaces for global land areas. International Journal of Climatology 37:4302-4315.

Fitter, A. H., and R. S. R. Fitter. 2002. Rapid Changes in Flowering Time in British Plants. Science 296:1689-1691.

Forrest, J., and J. D. Thomson. 2009. Pollinator experience, neophobia and the evolution of flowering time. Proc Biol Sci 276:935-943.

Frachon, L., C. Libourel, R. Villoutreix, S. Carrère, C. Glorieux, C. Huard-Chauveau, M. Navascués, L. Gay, R. Vitalis, E. Baron, L. Amsellem, O. Bouchez, M. Vidal, V. Le Corre, D. Roby, J. Bergelson, and F. Roux. 2017. Intermediate degrees of synergistic pleiotropy drive adaptive evolution in ecological time. Nature Ecology \& Evolution $1: 1551-1561$.

Franks, S. J., J. C. Avise, W. E. Bradshaw, J. K. Conner, J. R. Etterson, S. J. Mazer, R. G. Shaw, and A. E. Weis. 2008a. The Resurrection Initiative: Storing Ancestral Genotypes to Capture Evolution in Action. BioScience 58:870-873.

Franks, S. J., J. C. Avise, W. E. Bradshaw, J. K. Conner, J. R. Etterson, S. J. Mazer, R. G. Shaw, and A. E. Weis. 2008b. The Resurrection Initiative: Storing Ancestral Genotypes to Capture Evolution in Action. BioScience 58:870-873. 
647 Franks, S. J., and A. A. Hoffmann. 2012. Genetics of Climate Change Adaptation. Annu.

648

649

650

651

652

653

654

655

656

657

658

659

660

661

662

663

664

665

666

667

668

669

670 Rev. Genet. 46:185-208.

Franks, S. J., N. C. Kane, N. B. O’Hara, S. Tittes, and J. S. Rest. 2016. Rapid genome-wide evolution in Brassica rapa populations following drought revealed by sequencing of ancestral and descendant gene pools. Molecular Ecology 25:3622-3631.

Franks, S. J., S. Sim, and A. E. Weis. 2007. Rapid evolution of flowering time by an annual plant in response to a climate fluctuation. PNAS 104:1278-1282.

Frei, E. R., T. Hahn, J. Ghazoul, and A. R. Pluess. 2014. Divergent selection in low and high elevation populations of a perennial herb in the Swiss Alps. Alpine Botany 124:131142.

Gervasi, D. D. L., and F. P. Schiestl. 2017. Real-time divergent evolution in plants driven by pollinators. Nature Communications 8:14691.

Harder, L. D., and S. D. Johnson. 2009. Darwin's beautiful contrivances: evolutionary and functional evidence for floral adaptation. New Phytol. 183:530-545.

Harpaz, T., B. Ziv, H. Saaroni, and E. Beja. 2014. Extreme summer temperatures in the East Mediterranean — dynamical analysis. International Journal of Climatology 34:849_ 862.

Harris, I., P. D. Jones, T. J. Osborn, and D. H. Lister. 2014. Updated high-resolution grids of monthly climatic observations - the CRU TS3.10 Dataset. International Journal of Climatology 34:623-642.

Jacquemyn, H., L. De Meester, E. Jongejans, and O. Honnay. 2012. Evolutionary changes in plant reproductive traits following habitat fragmentation and their consequences for population fitness: Habitat fragmentation and plant trait evolution. Journal of Ecology 100:76-87. 
Jerome Goudet, T. J. 2015. hierfstat: Estimation and Tests of Hierarchical F-Statistics. R package version 0.04-22. https://CRAN.R-project.org/package=hierfstat.

673

674

675

676

677

678

679

680

681

682

683

684

685

686

687

688

689

690

691

692

693

Jombart, T. 2008. adegenet: a R package for the multivariate analysis of genetic markers. Bioinformatics 24:1403-1405.

Koprdova, S., S. Bellanger, J. Skuhrovec, and H. Darmency. 2015. Does gall midge larvae cause pre-dispersal seed mortality and limit cornflower population growth? Acta Oecologica 69:167-172.

Kuznetsova, A., P. B. Brockhoff, and R. H. B. Christensen. 2017. lmerTest Package: Tests in Linear Mixed Effects Models. Journal of Statistical Software 82:1-26.

Lambrecht, S. C., A. K. Gujral, L. J. Renshaw, and L. T. Rosengreen. 2020. Evolutionary and plastic changes in a native annual plant after a historic drought. Ecology and Evolution 10:4570-4582.

Lande, R., and S. J. Arnold. 1983. The Measurement of Selection on Correlated Characters. Evolution 37:1210-1226. [Society for the Study of Evolution, Wiley].

Le Corre, V., S. Bellanger, J.-P. Guillemin, and H. Darmency. 2014. Genetic diversity of the declining arable plant Centaurea cyanus: population fragmentation within an agricultural landscape is not associated with enhanced spatial genetic structure. Weed Research 54:436-444.

Leinonen, T., R. J. S. McCairns, R. B. O’Hara, and J. Merilä. 2013. QST-FST comparisons: evolutionary and ecological insights from genomic heterogeneity. Nature Reviews Genetics 14:179-190.

Lenormand, T. 2002. Gene flow and the limits to natural selection. Trends in Ecology \& Evolution 17:183-189. 
694 Lopez-Gallego, C., and P. O’Neil. 2010. Life-history variation following habitat degradation associated with differing fine-scale spatial genetic structure in a rainforest cycad. Population Ecology 52:191-201.

Nevo, E., Y.-B. Fu, T. Pavlicek, S. Khalifa, M. Tavasi, and A. Beiles. 2012. Evolution of wild cereals during 28 years of global warming in Israel. PNAS 109:3412-3415. National Academy of Sciences.

Niinemets, Ü., A. Portsmuth, D. Tena, M. Tobias, S. Matesanz, and F. Valladares. 2007. Do we Underestimate the Importance of Leaf Size in Plant Economics? Disproportional Scaling of Support Costs Within the Spectrum of Leaf Physiognomy. Ann Bot 100:283-303.

O’Brien, E. K., M. Higgie, A. Reynolds, A. A. Hoffmann, and J. R. Bridle. 2017. Testing for local adaptation and evolutionary potential along altitudinal gradients in rainforest

O’Hara, R. B. 2005a. Bias and Precision in QST Estimates: Problems and Some Solutions. Genetics 171:1331-1339.

O’Hara, R. B. 2005b. Bias and Precision in QST Estimates: Problems and Some Solutions. Genetics 171:1331-1339.

Parachnowitsch, A. L., and A. Kessler. 2010. Pollinators exert natural selection on flower size and floral display in Penstemon digitalis. New Phytologist 188:393-402.

Paradis, E., J. Claude, and K. Strimmer. 2004. APE: Analyses of Phylogenetics and Evolution in R language. Bioinformatics 20:289-290. Oxford Academic.

R Core Team. 2019. R: A language and environment for statistical computing. R Foundation for Statistical Computing, Vienna, Austria. URL https://www.R-project.org/.

717 Raguso, R. A. 2018. Floral scent in a whole-plant context: moving beyond pollinator attraction. Functional Ecology 23:837-840. 
Ramos, S. E., and F. P. Schiestl. 2019. Rapid plant evolution driven by the interaction of pollination and herbivory. Science 364:193-196. American Association for the Advancement of Science.

Renoult, J. P., M. Thomann, H. M. Schaefer, and P.-O. Cheptou. 2013. Selection on quantitative colour variation in Centaurea cyanus : the role of the pollinator's visual system. Journal of Evolutionary Biology 26:2415-2427.

Rhoné, B., R. Vitalis, I. Goldringer, and I. Bonnin. 2010. Evolution of flowering time in experimental wheat populations: a comprehensive approach to detect genetic signatures of natural selection. Evolution, doi: 10.1111/j.1558-5646.2010.00970.x.

Royer, D. L., P. Wilf, D. A. Janesko, E. A. Kowalski, and D. L. Dilcher. 2005. Correlations of climate and plant ecology to leaf size and shape: potential proxies for the fossil record. Am. J. Bot. 92:1141-1151.

Schemske, D. W., and R. Lande. 1985. The evolution of self-fertilization andinbreeding depression in plants. II. Empirical observations. Evolution 39:41-52.

Strauss, S. Y., and R. E. Irwin. 2004. Ecological and Evolutionary Consequences of Multispecies Plant-Animal Interactions. Annu. Rev. Ecol. Evol. Syst. 35:435-466.

Sultan, S. E., T. Horgan- Kobelski, L. M. Nichols, C. E. Riggs, and R. K. Waples. 2013. A resurrection study reveals rapid adaptive evolution within populations of an invasive plant. Evolutionary Applications 6:266-278.

Sun, S., and L. E. Frelich. 2011. Flowering phenology and height growth pattern are associated with maximum plant height, relative growth rate and stem tissue mass density in herbaceous grassland species. Journal of Ecology 99:991-1000.

Thomann, M., E. Imbert, C. Devaux, and P.-O. Cheptou. 2013. Flowering plants under global pollinator decline. Trends in Plant Science 18:353-359. 
Thomann, M., E. Imbert, R. C. Engstrand, and P.-O. Cheptou. 2015. Contemporary evolution of plant reproductive strategies under global change is revealed by stored seeds. Journal of Evolutionary Biology 28:766-778.

Thompson, J., A. Charpentier, G. Bouguet, F. Charmasson, S. Roset, B. Buatois, P. Vernet, and P.-H. Gouyon. 2013. Evolution of a genetic polymorphism with climate change in a Mediterranean landscape. Proc Natl Acad Sci U S A 110:2893-2897.

Tng, D. Y. P., G. J. Jordan, and D. M. J. S. Bowman. 2013. Plant Traits Demonstrate That Temperate and Tropical Giant Eucalypt Forests Are Ecologically Convergent with Rainforest Not Savanna. PLoS One 8.

Vtipil, E. E., and S. N. Sheth. 2020. A resurrection study reveals limited evolution of phenology in response to recent climate change across the geographic range of the scarlet monkeyflower. Ecol Evol 10:14165-14177.

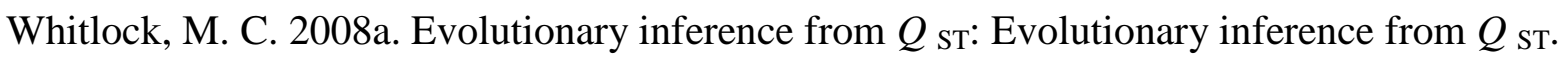
Molecular Ecology 17:1885-1896.

Whitlock, M. C. 2008b. Evolutionary inference from $Q$ sт: Evolutionary inference from $Q$ sт. Molecular Ecology 17:1885-1896.

Wilson, P. 2017. The Status of Centaurea cyanus in Britain. Nature England, PLANTLIFE 17.

Wooliver, R., S. B. Tittes, and S. N. Sheth. 2020. A resurrection study reveals limited evolution of thermal performance in response to recent climate change across the geographic range of the scarlet monkeyflower. Evolution 74:1699-1710.

Yu, Q., D.-R. Jia, B. Tian, Y.-P. Yang, and Y.-W. Duan. 2016. Changes of flowering phenology and flower size in rosaceous plants from a biodiversity hotspot in the past century. Scientific Reports 6. 
Zhu, K., N. R. Chiariello, T. Tobeck, T. Fukami, and C. B. Field. 2016. Nonlinear, interacting responses to climate limit grassland production under global change. Proceedings of the National Academy of Sciences 113:10589-10594.

Albrecht, H., J. Cambecèdes, M. Lang, and M. Wagner. 2016. Management options for the conservation of rare arable plants in Europe. Botany Letters 163:389-415.

Antonovics, J., A. D. Bradshaw, and R. G. Turner. 1971. Heavy Metal Tolerance in Plants. Pp. 1-85 in J. B. Cragg, ed. Advances in Ecological Research. Academic Press.

Austen, E. J., L. Rowe, J. R. Stinchcombe, and J. R. K. Forrest. 2017. Explaining the apparent paradox of persistent selection for early flowering. New Phytol 215:929_ 934.

Bates, D., M. Mächler, B. Bolker, and S. Walker. 2014. Fitting Linear Mixed-Effects Models using lme4. Journalf Statiscal Software arXiv1406(1).

Benjamini, Y., and Y. Hochberg. 1995. Controlling the False Discovery Rate: A Practical and Powerful Approach to Multiple Testing. Journal of the Royal Statistical Society. Series B (Methodological) 57:289-300. .

Blarer, A., T. Keasar, and A. Shmida. 2018. Possible Mechanisms for the Formation of Flower Size Preferences by Foraging Bumblebees. Ethology 108:341-351.

Bodbyl Roels, S. A., and J. K. Kelly. 2011. Rapid evolution caused by pollinator loss in Mimulus guttatus: rapid evolution after pollinator loss. Evolution 65:2541-2552.

Brys, R., and H. Jacquemyn. 2012. Effects of human-mediated pollinator impoverishment on floral traits and mating patterns in a short-lived herb: an experimental approach: Human-mediated pollinator impoverishment selects for autonomous selfing. Functional Ecology 26:189-197. 
791

792

793

794

795

796

797

798

799

800

801

802

803

804

805

806

807

808

809

810

811

812

813

814

815

816

817

Chambres d'agriculture des Pays de la Loire. 2013. Panorama socio-économique de l'agriculture des Pays de la Loire Données régionales et spécificités départementales.

Cheptou, P.-O., O. Carrue, S. Rouifed, and A. Cantarel. 2008. Rapid evolution of seed dispersal in an urban environment in the weed Crepis sancta. Proceedings of the National Academy of Sciences 105:3796-3799.

Dickman, E. E., L. K. Pennington, S. J. Franks, and J. P. Sexton. 2019. Evidence for adaptive responses to historic drought across a native plant species range. Evolutionary Applications 12:1569-1582.

Dijk, H. V., and N.-C. Hautekèete. 2014. Evidence of genetic change in the flowering phenology of sea beets along a latitudinal cline within two decades. Journal of Evolutionary Biology 27:1572-1581.

Doyle, J.J. a,d J.L. Doyle 1990. Isolation of plant DNA from fresh tissue. Focus 12: 13-15.

ENSCONET. 2009. Seed Collecting Manual for Wild Species. Available for download at http://www.ensconet.eu/Download.htm

Ferriere, R., and S. Legendre. 2012. Eco-evolutionary feedbacks, adaptive dynamics and evolutionary rescue theory. Philosophical Transactions of the Royal Society B: Biological Sciences 368:20120081-20120081.

Fick, S. E., and R. J. Hijmans. 2017. WorldClim 2: new 1-km spatial resolution climate surfaces for global land areas. International Journal of Climatology 37:4302-4315.

Fitter, A. H., and R. S. R. Fitter. 2002. Rapid Changes in Flowering Time in British Plants. Science 296:1689-1691.

Forrest, J., and J. D. Thomson. 2009. Pollinator experience, neophobia and the evolution of flowering time. Proc Biol Sci 276:935-943.

Frachon, L., C. Libourel, R. Villoutreix, S. Carrère, C. Glorieux, C. Huard-Chauveau, M. Navascués, L. Gay, R. Vitalis, E. Baron, L. Amsellem, O. Bouchez, M. Vidal, V. Le 

$1: 1551-1561$.

Franks, S. J., J. C. Avise, W. E. Bradshaw, J. K. Conner, J. R. Etterson, S. J. Mazer, R. G. Shaw, and A. E. Weis. 2008a. The Resurrection Initiative: Storing Ancestral Genotypes to Capture Evolution in Action. BioScience 58:870-873.

Franks, S. J., and A. A. Hoffmann. 2012. Genetics of Climate Change Adaptation. Annu. Rev. Genet. 46:185-208.

Franks, S. J., N. C. Kane, N. B. O’Hara, S. Tittes, and J. S. Rest. 2016. Rapid genome-wide evolution in Brassica rapa populations following drought revealed by sequencing of ancestral and descendant gene pools. Molecular Ecology 25:3622-3631.

Franks, S. J., S. Sim, and A. E. Weis. 2007. Rapid evolution of flowering time by an annual plant in response to a climate fluctuation. PNAS 104:1278-1282.

Frei, E. R., T. Hahn, J. Ghazoul, and A. R. Pluess. 2014. Divergent selection in low and high elevation populations of a perennial herb in the Swiss Alps. Alpine Botany 124:131142.

Gervasi, D. D. L., and F. P. Schiestl. 2017. Real-time divergent evolution in plants driven by pollinators. Nature Communications 8:14691.

Gómez, J. M. 2003. Herbivory Reduces the Strength of Pollinator- Mediated Selection in the Mediterranean Herb Erysimum mediohispanicum : Consequences for Plant Specialization. The American Naturalist 162:242-256.

Gómez-Martínez, C., A. L. T. O. Aase, Ø. Totland, J. Rodríguez-Pérez, T. Birkemoe, A. Sverdrup-Thygeson, and A. Lázaro. 2020. Forest fragmentation modifies the composition of bumblebee communities and modulates their trophic and competitive interactions for pollination. Scientific Reports 10:10872. 

potential future effects of habitat fragmentation on structure and stability of plantpollinator and host-parasitoid networks. Nature Ecology \& Evolution 2:1408-1417.

Harder, L. D., and S. D. Johnson. 2009. Darwin's beautiful contrivances: evolutionary and functional evidence for floral adaptation. New Phytol. 183:530-545.

Harpaz, T., B. Ziv, H. Saaroni, and E. Beja. 2014. Extreme summer temperatures in the East Mediterranean — dynamical analysis. International Journal of Climatology 34:849_ 862.

Harris, I., P. D. Jones, T. J. Osborn, and D. H. Lister. 2014. Updated high-resolution grids of monthly climatic observations - the CRU TS3.10 Dataset. International Journal of Climatology 34:623-642.

Jacquemyn, H., L. De Meester, E. Jongejans, and O. Honnay. 2012. Evolutionary changes in plant reproductive traits following habitat fragmentation and their consequences for population fitness: Habitat fragmentation and plant trait evolution. Journal of Ecology 100:76-87.

Goudet, T. J. 2015. hierfstat: Estimation and Tests of Hierarchical F-Statistics. R package version 0.04-22. https://CRAN.R-project.org/package=hierfstat.

Jombart, T. 2008. adegenet: a R package for the multivariate analysis of genetic markers. Bioinformatics 24:1403-1405.

862 Kuznetsova, A., P. B. Brockhoff, and R. H. B. Christensen. 2017. lmerTest Package: Tests in Linear Mixed Effects Models. Journal of Statistical Software 82:1-26.

864 Lambrecht, S. C., A. K. Gujral, L. J. Renshaw, and L. T. Rosengreen. 2020. Evolutionary and 865 plastic changes in a native annual plant after a historic drought. Ecology and Evolution 10:4570-4582. 
Lande, R., and S. J. Arnold. 1983. The Measurement of Selection on Correlated Characters. Evolution 37:1210-1226. .

Le Corre, V., S. Bellanger, J.-P. Guillemin, and H. Darmency. 2014. Genetic diversity of the declining arable plant Centaurea cyanus: population fragmentation within an agricultural landscape is not associated with enhanced spatial genetic structure. Weed Research 54:436-444.

Leinonen, T., R. J. S. McCairns, R. B. O’Hara, and J. Merilä. 2013. QST-FST comparisons: evolutionary and ecological insights from genomic heterogeneity. Nature Reviews Genetics 14:179-190.

Lenormand, T. 2002. Gene flow and the limits to natural selection. Trends in Ecology \& Evolution 17:183-189.

Lopez-Gallego, C., and P. O’Neil. 2010. Life-history variation following habitat degradation associated with differing fine-scale spatial genetic structure in a rainforest cycad. Population Ecology 52:191-201.

Martin, G., C. Fontaine, F. Accatino, and E. Porcher. 2019. New indices for rapid assessment 882 of pollination services based on crop yield data: France as a case study. Ecological wild cereals during 28 years of global warming in Israel. PNAS 109:3412-3415.

Niinemets, Ü., A. Portsmuth, D. Tena, M. Tobias, S. Matesanz, and F. Valladares. 2007. Do 887 we Underestimate the Importance of Leaf Size in Plant Economics? Disproportional Scaling of Support Costs Within the Spectrum of Leaf Physiognomy. Ann Bot 100:283-303. 
890 O’Brien, E. K., M. Higgie, A. Reynolds, A. A. Hoffmann, and J. R. Bridle. 2017. Testing for local adaptation and evolutionary potential along altitudinal gradients in rainforest Drosophila: beyond laboratory estimates. Global Change Biology 23:1847-1860.

O’Hara, R. B. 2005a. Bias and Precision in QST Estimates: Problems and Some Solutions. Genetics 171:1331-1339.

895 Parachnowitsch, A. L., and A. Kessler. 2010. Pollinators exert natural selection on flower 896 size and floral display in Penstemon digitalis. New Phytologist 188:393-402.

897 Paradis, E., J. Claude, and K. Strimmer. 2004. APE: Analyses of Phylogenetics and Evolution in R language. Bioinformatics 20:289-290.

Potts, S. G., V. Imperatriz-Fonseca, H. T. Ngo, M. A. Aizen, J. C. Biesmeijer, T. D. Breeze, 900 L. V. Dicks, L. A. Garibaldi, R. Hill, J. Settele, and A. J. Vanbergen. 2016. Safeguarding pollinators and their values to human well-being. Nature 540:220-229.

R Core Team. 2019. R: A language and environment for statistical computing. R Foundation 903 for Statistical Computing, Vienna, Austria. URL https://www.R-project.org/.

904 Raguso, R. A. 2018. Floral scent in a whole-plant context: moving beyond pollinator 905 attraction. Functional Ecology 23:837-840.

906

Ramos, S. E., and F. P. Schiestl. 2019. Rapid plant evolution driven by the interaction of 907 pollination and herbivory. Science 364:193-196.

908

Renoult, J. P., M. Thomann, H. M. Schaefer, and P.-O. Cheptou. 2013. Selection on 909

910 quantitative colour variation in Centaurea cyanus : the role of the pollinator's visual

911 Rhoné, B., R. Vitalis, I. Goldringer, and I. Bonnin. 2010. Evolution of flowering time in 912 experimental wheat populations: a comprehensive approach to detect genetic signatures of natural selection. Evolution, doi: 10.1111/j.1558-5646.2010.00970.x. 
914 Royer, D. L., P. Wilf, D. A. Janesko, E. A. Kowalski, and D. L. Dilcher. 2005. Correlations of climate and plant ecology to leaf size and shape: potential proxies for the fossil record. Am. J. Bot. 92:1141-1151.

917 Schemske, D. W., and R. Lande. 1985. The evolution of self-fertilization andinbreeding depression in plants. II. Empirical observations. Evolution 39:41-52.

919 Strauss, S. Y., and R. E. Irwin. 2004. Ecological and Evolutionary Consequences of 920 Multispecies Plant-Animal Interactions. Annu. Rev. Ecol. Evol. Syst. 35:435-466.

Sultan, S. E., T. Horgan- Kobelski, L. M. Nichols, C. E. Riggs, and R. K. Waples. 2013. A resurrection study reveals rapid adaptive evolution within populations of an invasive plant. Evolutionary Applications 6:266-278.

Sun, S., and L. E. Frelich. 2011. Flowering phenology and height growth pattern are 925 associated with maximum plant height, relative growth rate and stem tissue mass density in herbaceous grassland species. Journal of Ecology 99:991-1000.

Thomann, M., E. Imbert, C. Devaux, and P.-O. Cheptou. 2013. Flowering plants under global pollinator decline. Trends in Plant Science 18:353-359.

Thomann, M. 2014 Evolution des stratégies de reproduction des plantes à fleurs face aux 930 changements globaux et au déclin des pollinisateurs Thèse de doctorat Université Montpellier 2.

Thomann, M., E. Imbert, R. C. Engstrand, and P.-O. Cheptou. 2015. Contemporary evolution of plant reproductive strategies under global change is revealed by stored seeds. Journal of Evolutionary Biology 28:766-778.

936 Thompson, J., A. Charpentier, G. Bouguet, F. Charmasson, S. Roset, B. Buatois, P. Vernet, 937 and P.-H. Gouyon. 2013. Evolution of a genetic polymorphism with climate change in a Mediterranean landscape. Proc Natl Acad Sci U S A 110:2893-2897. 
Tng, D. Y. P., G. J. Jordan, and D. M. J. S. Bowman. 2013. Plant Traits Demonstrate That Temperate and Tropical Giant Eucalypt Forests Are Ecologically Convergent with Rainforest Not Savanna. PLoS One 8.

Vtipil, E. E., and S. N. Sheth. 2020. A resurrection study reveals limited evolution of phenology in response to recent climate change across the geographic range of the scarlet monkeyflower. Ecol Evol 10:14165-14177.

Weis, A. E. 2018. Detecting the "invisible fraction" bias in resurrection experiments. Evolutionary Applications 11:88-95.

Whitlock, M. C. 2008. Evolutionary inference from $Q$ sT: Evolutionary inference from $Q$ sт. Molecular Ecology 17:1885-1896.

Wilson, P. 2017. The Status of Centaurea cyanus in Britain. Nature England, PLANTLIFE

950 17.

951

Wooliver, R., S. B. Tittes, and S. N. Sheth. 2020. A resurrection study reveals limited evolution of thermal performance in response to recent climate change across the geographic range of the scarlet monkeyflower. Evolution 74:1699-1710. phenology and flower size in rosaceous plants from a biodiversity hotspot in the past century. Scientific Reports 6. responses to climate limit grassland production under global change. Proceedings of the National Academy of Sciences 113:10589-10594.

960 